\title{
La lectora de periódicos
}

\author{
The Newspaper Reading Women
}

A leitora de jornais

\section{Graciela Batticuore}

UNIVERSIDAD DE BUENOS AIRES/CONSEJO NACIONAL DE INVESTIGACIONES CIENTÍFICAS Y

TÉCNICAS (CONICET), ARGENTINA

Investigadora independiente del Conicet y profesora a cargo de la

cátedra de Literatura Argentina I en la Universidad de Buenos Aires,

Argentina. Doctora en Letras por la Universidad de Buenos Aires.

Es autora, entre otros, de Mariquita Sánchez. Bajo el signo de la

revolución (Edhasa, 2011), La mujer romántica. Lectoras, autoras y

escritores en la Argentina: 1830-1870 (Primer Premio de Ensayo Fondo

Nacional de las Artes, Edhasa, 2005). También de varios volúmenes

colectivos en colaboración: Sarmiento en intersección. Cultura,

literatura y política en Argentina (Eudeba 2012), Tres momentos de

la cultura argentina: 1810, 1910, 2010 (Prometeo, 2012), Fronteras

escritas. Límites, desvíos y pasajes en la literatura argentina (Beatriz

Viterbo, 2008) y Resonancias románticas. Ensayos sobre historia de

la cultura argentina. 1810-1890 (Eudeba, 2005), entre otros. Prepara

actualmente Lectoras: imaginarios y prácticas en Argentina (Capital

Intelectual, 2016). Correo electrónico: gbatticuore@gmail.com

\section{Artículo de reflexión}

Documento accesible en línea desde la siguiente dirección: http://revistas.javeriana.edu.co

doi:10.11144/Javeriana.cl20-40.IIdp 


\section{Resumen \\ ¿Cuándo emergen las primeras representaciones de la mujer lectora en la Argentina del siglo XIX? ¿Qué relevancia adquiere su perfil en los debates político-culturales de la época revolucionaria? ¿Qué leen las mujeres en la prensa y cómo responden a la invocación de los redactores que diseñan para ellas políticas educativas y programas de lectura? El artículo intenta responder a estas interrogantes por medio de un corpus selecto de periódicos de comienzos de siglo (El Telégrafo Mercantil, El Semanario de Agricultura y Comercio, El Correo del Comercio, El Observador Americano, La Gazeta de Buenos Aires). De igual modo, el artículo indaga en representaciones literarias y artísticas para desentrañar los imaginarios y prácticas de la mujer lectora en los orígenes de la formación nacional.}
Palabras clave: prensa; periódicos; siglo XIX; Argentina; Nación; lectores; lectora; lectura; cultura femenina; literatura argentina

\section{Abstract}

When do the first representations of newspaper reading women in the 19th Century Argentina begin to appear? What is the relevance of their profile in the politicalcultural debates of the revolutionary era? What do women read in the press, and how do they answer to the call of writers designing educational policies and reading programs for them? This article aims to answer these questions by means of a select corpus of newspapers from the beginning of the century (El Telégrafo Mercantil, El Semanario de Agricultura y Comercio, El Correo del Comercio, El Observador Americano, La Gazeta de Buenos Aires). Likewise, the article delves into literary and artistic representations to figure out the imaginaries and practices of reading women at the origins of the formation of the nation.

Keywords: press; newspapers; 19th century; Argentina; nation; readers; reading women; women culture; Argentinian literature

\section{Resumo}

Quando é que as primeiras representações da mulher leitora na Argentina do século XIX surgem? Qual a relevância do seu perfil em debates político-culturais da época revolucionária? O que as mulheres lêem nos jornais e como respondem à invocação dos redatores que concebem políticas educativas e programas de leitura para elas? $\mathrm{O}$ artigo visa responder a estas interrogantes a través de um corpus seleto de jornais de começos de século (El Telégrafo Mercantil, El Semanario de Agricultura y Comercio, El Correo del Comercio, El Observador Americano, La Gazeta de Buenos Aires). Mesmo, $o$ artigo indaga em representações literárias e artísticas para desvendar os imaginários e práticas da mulher leitora nas origens da formação nacional.

Palavras-chave: imprensa; jornais; século XIX; Argentina; Nação; leitores; leitora; leitura; cultura feminina; literatura argentina 


\section{Leyendo para las mujeres}

Imaginemos que estamos ante un cuadro costumbrista de mediados del siglo XIX, que tiene por asunto principal el motivo de la lectura en voz alta, compartida, en un ambiente familiar donde predominan las mujeres. Sería así: un hombre entrado en años yace cómodamente apoyado en un sillón francés mullido, las piernas cruzadas, la nuca descansando sobre el respaldo, el periódico abierto, ligeramente arrugado entre las manos. A su izquierda, otro caballero más joven lo contempla mientras toma un mate, está reclinado sobre el perfil de una ventana alta por la que se filtra la luz matinal que riega el interior de una acogedora habitación burguesa donde transcurre la escena. De derecha a izquierda, terminando casi en frente del lector, se suceden en posiciones diversas tres mujeres: una criada negra que aguarda órdenes, una joven bonita que yace sentada, bordando, sobre una gran cama estilo imperial donde su madre (o quizá su abuela) se encuentra recostada y arropada, saboreando también ella un mate, mientras escucha y observa, a su vez, al hombre que lee para ellas en voz alta. Sobre la cama caen los velos de un rico cortinado; sobre el piso se despliega una mullida alfombra recamada; sobre las mesitas que coronan la habitación hay un jarrón de agua para acicalarse y, por supuesto, una lámpara a vela que servirá para iluminar la estancia cuando caiga la noche.

Ese cuadro lo pintó sobre un lienzo, al óleo, el artista argentino Prilidiano Pueyrredón, sin duda, por encargo de un jefe de familia que deseaba perpetuar así la memoria de su prole, en una pose a la vez apacible y distinguida. Familia de don Pedro Bernal y una criada, se llama la obra, no muy conocida, porque tan solo circuló esporádicamente, reproducida en las páginas de algunos estudios del crítico José León Pagano, a comienzos del siglo XX, mientras el lienzo permanecía al albergo de sus propietarios (probablemente, de los descendientes de Bernal), en colección particular. Cabe preguntarse, por ejemplo, aunque la respuesta sea bastante evidente, por qué Bernal habría elegido representar a su familia en esta escena doméstica, íntima y matutina donde conviven los extremos (el señor que lee y la criada que sirve, muy probablemente, una mujer iletrada). $\mathrm{Y}_{\mathrm{d}} \mathrm{dó}$ de, en qué lugar de la casa habría querido el propietario exhibir este lienzo de medidas pequeñas (apenas $32 \times 42$, el tamaño, casi, de un retrato portátil)? ${ }_{\mathrm{C}}$ Con qué marco lo habría revestido? ¿Para qué usos lo había imaginado? ¿Tan solo para perpetuar la memoria de una familia culta y distinguida (la suya propia)? $\mathrm{O}_{\mathrm{C}}$ acaso para constatar y dejar bien asentado ante el círculo de amigos y allegados, por ejemplo, los habitués de las tertulias hogareñas que frecuentarían su casa en esa misma época, que efectivamente lo eran? Por cierto, a mediados del siglo XIX, es decir, bajo la estela subyugante del romanticismo que tiñó casi toda la centuria — desde 
mediados de la década de los veinte, aproximadamente, en adelante- retratarse leyendo o escribiendo implicaba todo un signo de distinción social que ennoblecía al retratado, lo ubicaba en su entorno y, a veces, también, lo connotaba políticamente. Esto último lo ilustran a la perfección, ya antes de Pueyrredón, unas cuantas obras confeccionadas por Carlos Enrique Pellegrini entre fines de 1820 y mediados de 1830 , cuando compone el perfil de hombres y mujeres de la alta sociedad porteña que aparecen rodeados de libros, manuscritos, cartas o bibliotecas, envueltos a veces en una trama de veladas significaciones políticas. Podemos citar algunos casos conocidos, por ejemplo, el bellísimo retrato de Lucía Carranza que sostiene entre sus manos el Telémaco de Fenelón. O el de Fernández de Agüero o de Manuel Antonio Castro, que aparecen rodeados de manuscritos y plumas, con un libro de su autoría entre las manos, que evoca un episodio conflictivo de su biografía política. $\mathrm{O}$ el de la señora Botet de Senillosa, que sostiene un pequeño librito con el título Beneficencia, en alusión a su actividad como secretaria administrativa y contable de la institución que fundó Bernardino Rivadavia en los años veinte (la Sociedad de Beneficencia), ya bajo el gobierno de Juan Manuel de Rosas. Además de ellos, muchas otras porteñas quisieron ser retratadas también por Pellegrini con libros o esquelas entre sus manos: doña Andrea Ibáñez de Anchorena, doña Aniceta Villariño de Lagos, doña Feliciano Ugalde de Maldonado, doña Francisca Ambroa de Alsina, doña Isabel Agüero de Ugalde, doña Manuela Aguirre de García, doña Mercedes Anchorena de Aguirre, doña Segundina de la Iglesia de Castellanos. Solas o acompañadas por sus hijos o esposos, todas ellas han querido ser recordadas por la posteridad como lectoras.

$\mathrm{Y}$, sin embargo, aunque la serie que pinta Pellegrini es vasta, y por demás significativa, no encontramos entre esos retratos femeninos a ninguna mujer lectora de periódicos: ninguna que lea por sí misma o que se entere de lo que dice la prensa a través de la voz de un mediador, como sucede, en cambio, en la obra de la familia Bernal que compuso Prilidiano Pueyrredón. Él sí coloca la escena de lectura del periódico en primer plano en ese cuadro costumbrista presuntamente apacible, cuasi fotográfico, que se presenta ante los ojos de los espectadores como salido "del natural". Y en el que la lectura compartida parece estar exenta de toda peligrosidad: es decir, todo aparenta estar allí a resguardo, colocado "en su lugar". Me refiero al hecho de que el retrato ofrece una perspectiva tradicional y muy cara al siglo XIX (aunque esta configuración deje de lado otras complejidades de la vida real): nos dice que la lectura del periódico es una ceremonia cotidiana que está directamente ligada al protagonismo masculino, más propiamente al hombre de la casa. Él domina la escena: él lee para las mujeres; él selecciona, recorta, 
organiza, supervisa, administra, da a conocer a las mujeres de su entorno lo que a ellas conviene o debe interesar. El hombre es el mediador, el guía y el maestro de lectura femenina (desde luego, esto se reitera en otra serie de representaciones literarias del siglo XIX que exceden el coto exclusivo de la lectura de periódicos). Por su parte, ellas hacen bien lo suyo: sirven, si son criadas; descansan, si son ancianas o están entradas en años o bordan, si son jóvenes y están en edad de merecer. Mientras realizan cualquiera de estas otras actividades que les son propias, además, se ilustran un poco acerca de lo que informan los periódicos. Puede decirse, así, que el señor Bernal y familia - tanto como su retratista - se atienen a las preferencias o las prescripciones moralistas de su siglo, que alertan cuidados y precauciones con las lectoras: cuidado con los libros que llegan a sus manos, especial cuidado con las novelas. Y cuidado, también, con los periódicos, que hasta muy entrado el siglo XIX en el Río de la Plata, participan activamente de la guerra de ideas y de la lucha facciosa. Precisamente, debido a que la prensa está estrechamente ligada con los asuntos públicos es que aparece más asociada con las prácticas de lectura y escritura de los hombres. En cambio las lectoras, si se retratan como tales, prefieren hacerlo con un misal, un libro, una carta en la mano. Eso explica, al menos en parte, que en la familia Bernal las mujeres se enteren de las noticias a través del hombre de la casa. A la hora de ser representadas sobre el lienzo, de elegir una imagen a través de la cual pueden ser observadas por los contemporáneos o evocadas por la posteridad, ellas no se muestran directamente leyendo el periódico: por cierto, en esta pintura las mujeres ni siquiera lo palpan.

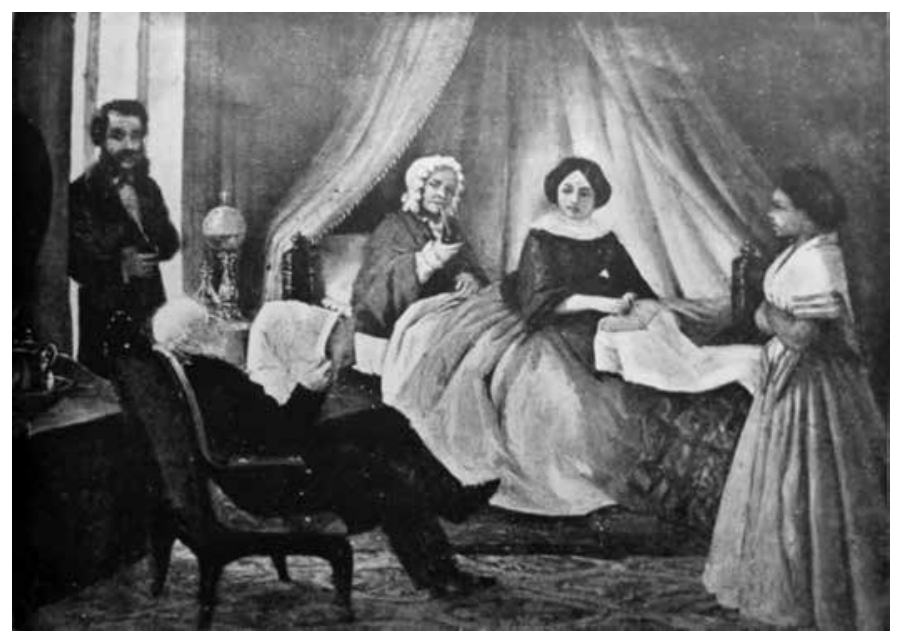

Prilidiano Pueyrredón, Familia de don Pedro Bernal y una criada. Colección privada 
Claro que estamos en la casa de una familia burguesa, probablemente de una familia de la élite porteña de mediados de siglo. Así que la perspectiva de Pueyrredón no es original, sino que busca su acierto en los ideales de un sector social y de una época. Por eso no sorprende que algo de lo que encontramos en ese retrato familiar se reitere, bajo una clave diferente, en otro lienzo de Benjamin Franklyn Rawson, pintado en 1867, titulado Escena interior. De nuevo tenemos allí a una joven escoltando a un lector. ¿Se trata de una criada o de una muchacha de familia? No hay otras mujeres adultas en la escena; tan solo una niña que acompaña, un poco atrás del hombre, y que parece estar ajena a la lectura que él practica en silencio (al igual que la joven aunque por razones diversas: no es tan solo la clase social o el género, sino también la edad, lo que la deja a la niña fuera de la situación de lectura del periódico). El hombre esta vez no lee en voz alta, sino que lo hace para sí. La lectura es aquí el goce, ¿el lujo?, de un señor burgués que mientras lee y se ilustra, es bien servido en sus necesidades de hombre de mundo: la joven se ocupa de acondicionar el ambiente para que él pueda leer. Ella sujeta en sus manos un pabilo con el que acaba de encender la vela que ilumina la escena mientras él, insisto, lee cómodamente el diario. Antes o después lo aguarda también la lectura de un libro; eso sugiere la presencia de un volumen cerrado en la esquina de la mesa.

Sin embargo, no hay que dejarse engañar por la impresión que ofrece el cuadro a primera vista: es cierto que la mujer no lee (ni tampoco le leen, en este caso), o sea que saber lo que dice el periódico es un lujo que a ella no le cabe. Pero es cierto, así mismo, que la cultura impresa y las noticias forman parte del ambiente cotidiano de esta joven que probablemente esté habituada a asistir a los raptos emotivos del señor de la casa cuando este se entera, por ejemplo, leyendo el diario, de cualquier noticia de implicancias políticas, sociales o comerciales que puedan afectarlo. Ni en el cuadro de Rawson que, dicho sea de paso, fue el pintor favorito de Sarmiento, ni en el de Pueyrredón, las mujeres permanecen ajenas a la prensa, sean ellas señoras o criadas. Porque, al igual que sucede en la vida moderna con los iletrados de cualquier parte del mundo, sobre todo en el ambiente urbano donde los sujetos - sepan o no leer y escribir - guardan con los escritos relaciones disímiles, las criadas y aún las esclavas asisten también, de un modo u otro, a las novedades que ofrecen los periódicos día tras día, y que resultan un material de consumo tan atractivo como indispensable para los señores, las señoras y el resto de los sujetos que forman parte de su casa, a medida que el siglo avanza. 


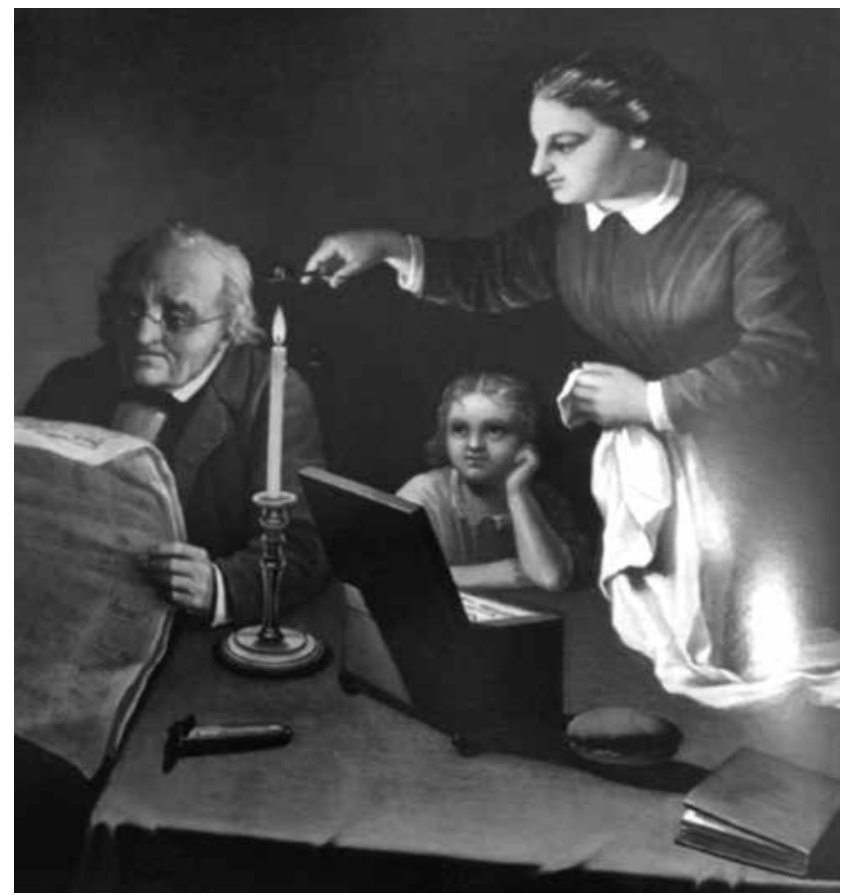

Benjamin Franklyn Rawson, Escena interior. Colección privada

\section{Primeras lectoras y corresponsales}

Fuera de éstas y otras pocas imágenes, en el arte argentino del siglo XIX la representación de la mujer lectora de periódicos no abunda. Me atrevería a decir otro tanto del arte europeo decimonónico en general, aunque esta situación se modifica en las primeras décadas del siglo XX, cuando las mujeres son ya eximias lectoras de periódicos y semanarios, de magazines ilustrados o revistas de moda que se imprimen exclusivamente para ellas y en los que colaboran, además, asiduamente, como redactoras. Sin embargo, la literatura tanto como los ensayos y otros registros discursivos que corren en el interior mismo de la prensa decimonónica sí dan sobrada cuenta, desde muy temprano, de la presencia de lectoras: reales o imaginadas, elogiadas, amonestadas o temidas; ellas han sido constantemente interpeladas por escritores y publicistas, a menudo con el propósito de modelar su perfil de acuerdo con las expectativas, los necesidades o las urgencias de las diversas épocas.

¿Cuándo asoman esas primeras representaciones de la mujer lectora de periódicos en la Argentina del siglo XIX? Irrumpen exactamente con la aparición de los primeros semanarios porteños, allá por 1801, cuando se publica en Buenos 
Aires El Telégrafo Mercantil, dirigido por Hipólito Vieytes, y, poco después, en 1802, El Semanario de Agricultura y Comercio, a cargo de Cabello y Mesa. Entre sus páginas comienza a desenvolverse tímidamente lo que a lo largo de la centuria constituirá un tópico: el nexo entre educación de la mujer, civilización y progresos en los países jóvenes de América.

"SSerá posible que se educa tan mal a esta preciosa mitad de nuestra especie?", se pregunta un redactor del Semanario en mayo de 1804 . Y en seguida reflexiona así:

[...] yo no digo que indistintamente se dirija a todas las mujeres por el camino de la ilustración y del buen gusto, porque el tiempo necesario para cultivar su razón lo necesitan las gentes pobres para ocuparlo en la labor, y para enseñarlas a reconcentrarse del todo en el cuidado y conocimiento de las cosas domésticas pero ¿̇por qué a las mujeres de fortuna no se les había de enseñar alguna parte de la historia, de la moral, de la filosofía, de la geografía y de la botánica? ¿Por qué a lo menos no se les había de hacer aprender a hablar el idioma patrio con pureza y precisión? ("Educación" f. 305; las cursivas son mías)

Mientras este redactor alienta exclusivamente la ilustración de las mujeres de clase alta, y otro alega que entre las porteñas existen muchas damas instruidas que sí leen, escriben y hasta hablan en otras lenguas, se asoma veladamente en otro número del semanario la voz de una traductora que se encargó de verter, del francés al español, el artículo de un célebre naturalista del siglo XVIII. El Conde de Bufón (aquí bajo la firma de Lecrec), de él se trata, defiende en dicho artículo la instrucción de las mujeres "de cualquier condición que sean", en bien de la civilización y las buenas costumbres de los pueblos. A través de esas opiniones y en cotejo con la de los otros redactores, la divergencia sobre la necesidad de educar a las mujeres de clase baja o tan solo a las damas de la élite queda explícitamente planteada. Y con ella puede decirse que se esboza en la prensa porteña del siglo XIX, por primera vez, el imaginario de la lectora pobre, que será retomado pocos años después en el contexto acuciante de la revolución de mayo, cuando la necesidad de ganar al pueblo a favor de la "nueva causa" anime a los líderes revolucionarios a decidir una serie de medidas político-culturales de urgencia, que tuvieron por objeto propiciar la democratización de la lectura entre los diversos sectores de la población. La apertura de la Biblioteca Pública de Buenos Aires, en 1812, la convocatoria a la creación de una marcha patriótica, el proyecto de publicar una colección de libros que divulgaran el nuevo ideario y, en ese marco, la traducción que hizo Mariano Moreno del Contrato Social de Rousseau fueron algunas de esas medidas por medio de las cuales se intentaron solventar, desde la 
esfera cultural, los grandes cambios en materia política. Ese mismo espíritu llevó a Manuel Belgrano, en 1810, a introducir en las páginas de El Correo del Comercio una serie de artículos sobre educación popular que prestan particular atención a la situación de las mujeres. Lo peculiar, en este caso, es que el redactor del semanario acude a un recurso novedoso: esta vez es la voz de una lectora la que se hace oír sobre el tema, al celebrar las propuestas sobre educación popular que alienta la publicación e intentando aportar sus propias consideraciones sobre el asunto. Conviene sacar del olvido las palabras de aquella anónima lectora, entre otras cosas porque constituyen el primer registro periodístico argentino de la corresponsalía femenina:

Yo, Señores Editores, me he atrevido a tomar la pluma para proponer un medio fácil con que se puede conseguir un fin tan santo, $\mathrm{y}$ en particular por respecto a mi sexo, que es el que más necesita de aquellos auxilios [...] He leído algunos libros que por fortuna me han venido en manos, que tratan del modo con que las Sociedades cultas se ha pensado en socorrer a los pobres, trayéndolos al camino más ventajoso para que no sean una carga pesada a sus conciudadanos, y con utilidad suya puedan hacer la causa común.

Entre ellos encontré una noticia exacta de las Juntas de Caridad que hay establecidas en las Parroquias de Madrid, sin otro objeto que el de amparar al verdadero pobre, y ese pensamiento me ha llenado tanto, que estaba ansiosa de publicarlo, y sintiendo que en esta nuestra Patria no hubiese un Periódico en el que pudiera salir a luz.

Agitada con aquel deseo, y cuando más sentimiento tenía de no serme posible verificarlo, me encontré con el Prospecto de su Correo de Comercio en casa de una amiga mía, que compra cuanto papel sale de la Imprenta, y me lo devoré instantáneamente, para saber si habría lugar al pensamiento de mi predilección.

No pueden ustedes persuadirse cuanta fue mi complacencia al contemplar que ya se había abierto el camino para ver de letra de molde mis ideas, y que estas llegarían a penetrar en las casas de esos vecinos distinguidos que tanta caridad manifiestan, y que hereándose los sentimentos cristianos han dado y dan santas pruebas de ellos, como nos los están manifestando los Templos, los Conventos, los Hospitales, y por consecuencia obrarían en ellos todos los efectos que me he figurado. (Correo del Comercio, 28 abr 69)

La nota continúa con más ideas de la lectora sobre cómo llevar a cabo el proyecto que a ella y a los editores del Correo... interesa. En primer lugar, hay que notar que su propuesta se plantea bajo los términos en los que, ciertamente, 
se iría efectivizando, tan solo una década después, la alfabetización femenina en Buenos Aires: es decir, a través de la acción de un grupo de mujeres provenientes de la élite que se hacen cargo de la educación de las niñas pobres de la ciudad, en el marco institucional que les provee el Gobierno (me refiero a la Sociedad de Beneficencia, creada por Bernardino Rivadavia, en 1824: primera institución pública en la que participan mujeres). Por otra parte, la corresponsal del Correo encomia el hecho de que la experiencia pedagógica que propone el semanario, y que ella tanto celebra, ya se ha puesto a prueba exitosamente en algunas sociedades europeas: España es el modelo que tiene en mente. $\mathrm{Y}$ aunque no se lo diga explícitamente, ese modelo se recuesta sobre la vieja noción de caridad que propiciaba el catolicismo religioso, y que encuentra ahora una expresión más aggiornada en el término beneficencia.

Por lo demás, los párrafos citados más arriba ilustran también otras cuestiones en las que vale la pena detenerse. En primer lugar, ponen en escena un tipo de lectura (y de lectora) signada por el ansia de consumo: la suscriptora amiga de la corresponsal y, según puede entreverse, también ella, leen "cuanto les cae en las manos". Es decir, leen vorazmente, con pasión. Y eso mismo lleva a la redactora a tener ideas propias sobre el asunto, y a querer expresarlas. Más aún: la mujer recuerda la emoción que experimentó ante su primer encuentro con las páginas del Correo, cuando después de leer las propuestas sobre educación popular, entendió que estas sintonizaban perfectamente con sus propias ideas y vislumbró entonces un camino para verlas reproducidas "en letras de molde". Esta declaración me interesa porque sitúa la primera representación en la prensa argentina —o tal vez sería más ajustado decir: la primera escenificación, ya que está esbozada de manera bastante dramática - de un hecho delicado que dará bastante que hablar a lo largo del siglo XIX (especialmente en las primeras décadas): me refiero al pasaje de la lectura a la escritura femenina y, más concretamente, a la autoría. Porque, como bien lo expresa la lectora en cuestión: ella "estaba ansiosa de publicar" (Correo del Comercio, 28 abr 69).

Sin dudas es el contexto acuciante de la revolución lo que habilita estas manifestaciones, también las propuestas o los reclamos que se irán sumando de aquí en más, y que en el escenario local suponen un primer paso en la toma de conciencia acerca de los "derechos" de las mujeres como sujetos sociales y políticos: derechos, por ahora, a instruirse, a estar informadas, y también a colaborar activamente en la educación de "las más débiles" del género:

1 Desarrollo el tema y exploro las modalidades de la lectura y la autoría femenina en el siglo XIX en La mujer romántica. Lectoras, escritores y autoras en la Argentina, 1830-1870. 
[...] añadiré solamente una ocurrencia [...] se podrían asociar las personas de mi sexo a esas Hermandades, con el objeto de atender a los establecimientos de enseñanza de las niñas, y socorro de las mujeres pobres [...]. Creo positivamente que esto importaría mucho; porque en nosotras hay una sensibilidad que en los varones, nos agradan estas ocupaciones, y también nos picamos de manifestar con nuestro celo y eficacia, que no somos menos aptas que ellos para desempeñar lo que se nos encarga en asuntos que parece salen de la esfera de lo que hacen nuestra principal intención diaria, que aunque es verdadera no son de menos importancia al Estado, que los grandes negocios, con todo, gustamos entrar en ellos, y no vivir eternamente condenadas a tratar de cosas caseras, y que el público no conozca nuestro mérito. (Correo del Comercio, 5 may 76 )

Resulta bien interesante la perspectiva de esta lectora temprana, devenida en resuelta corresponsal, si la cotejamos nuevamente con la pintura de Pueyrredón, donde las mujeres representadas parecen tan confortablemente inmersas en el ambiente doméstico: la cama mullida, el bordado, las tareas de servicio... En cambio, en las reflexiones de esta supuesta corresponsal de comienzos de siglo se asoma subrepticiamente la amenaza de la domesticidad: de pronto "lo casero" es susceptible de tornarse en "condena" para las mujeres, si no se las habilita socialmente para cruzar el cerco de la vida familiar e intervenir más o menos activamente en lo público, ese otro territorio completamente sujeto a las reglas y los protagonismos masculinos.

Así las cosas, la cuestión invita a seguir imaginando un poco más sobre la familia Bernal: por ejemplo, ¿qué habrían hecho las mujeres de la casa después de aquel momento de sociabilidad matutina tan sugerente, gobernado en apariencia por la voz del padre de familia que deja entrar, a través del periódico, "el mundo" en casa? ¿Habrían salido, ellas también, a explorar la agitación de las calles porteñas, a participar de alguna otra actividad no resueltamente doméstica? ¿Habrían saltado esa valla restrictiva de la vida privada que hace temer a la corresponsal del Correo...? No lo sabemos. Pero sí que los primeros periódicos porteños, sobre todo los de la década revolucionaria, contribuyeron a abrir $-\mathrm{y}$ a plasmar - un horizonte de inquietudes para las mujeres del siglo: por lo pronto, esas publicaciones proveyeron el espacio para la expresión de algunos reclamos que seguirían estando muy presentes en las décadas siguientes. E introdujeron la noción de igualdad intelectual, a partir de la idea de que los hombres de distintos estamentos sociales, y quizás también las mujeres, podían concebirse como "sujetos de derecho" (un tópico, sin duda, que la Revolución Francesa 
hizo candente en Europa). De allí que sea posible encontrar en las páginas de aquellos semanarios del período revolucionario los primeros retratos individuales y colectivos de la mujer lectora de libros y periódicos.

$\mathrm{Al}$ respecto, resulta muy ilustrativo, también, indagar un poco en $\mathrm{El} \mathrm{Ob}$ servador Americano: publicado en 1816, en Buenos Aires, dirigido por Manuel Antonio Castro (uno de los redactores del Estatuto Provisional de 1815 y de la Constitución Unitaria del 26). Este fue el primer semanario porteño que dedicó una sección fija, en cada uno de sus números, al tema de la educación de las mujeres. Desde su inicio se propuso desplegar "planes" de lectura para las mujeres que, sin embargo, no llegaron a concretarse. De todos modos, El Observador se encargó de reiterar consejos o prescriptivas generales: que las damas se cuidaran de la influencia de las novelas y que realizaran tan solo lecturas útiles, en los tiempos que les dejaran "libres" las tareas domésticas, sugería. Es decir, que hicieran un uso moderado de la lectura. También que se alejaran de una moda que parecía estar haciendo furor en las tertulias porteñas: la conversación banal, la pedantería parlanchina de las mujeres que hacían alarde de lo que sabían o habían leído, sin darse cuenta de que resultaban "ridículas". Y a raíz de estas recomendaciones, precisamente, después de algunos números, las lectoras de El Observador se hicieron visibles, también ellas, a través de la corresponsalía.

Con la primera carta dirigida al semanario, el 16 de setiembre de 1816, asoma en esta publicación otra novedad interesante: la referencia a una sociedad de lectura femenina, que firma la carta de lectoras bajo la denominación Amigas del Observador. Se trata de un conjunto de mujeres que dice reunirse cada lunes (día en que sale el semanario) para leer juntas el periódico, analizarlo y entrar en diálogo con los editores: "nos hemos propuesto el de reducir a la práctica todos los consejos que dan Ud. a las personas de nuestro sexo en general y comunicarles el fruto de nuestros ensayos". Y, efectivamente, así parecen hacerlo en esta misma ocasión, en la que aprovechan para poner de manifiesto sus críticas: que las propuestas de educación que ofrece El Observador resultan "ambiguas", sostienen, y, además, que los juicios que ellos enarbolan sobre los "vicios" de las mujeres (esto es, que ellas leen mucho, que hablan demasiado) son exagerados. Y que, en todo caso, para "corregirlas" - como el semanario pretende - no hay que dedicarse tanto a criticarlas, sino a estimularlas a leer más cosas. Empezando por publicar los planes que han prometido y sobre los que no han avanzado nada hasta el momento:

Por otra parte para que corrijamos nuestros defectos que bien los conocemos sin que no los adviertan, es preciso que se nos estimule con la esperanza de algunas ventajas de que nos hallamos privadas. Para continuar en la humillación 
de nuestro destino con menos pena, casi es conveniente que seamos estúpidas; si Us. se han propuesto hacer menos abatida nuestra suerte, empiecen por anunciar esas grandes mejoras, y esa importancia que habremos de tener en la sociedad como una consecuencia de sus planes. Si las mujeres concebimos que pueden algún día realizarse, es natural que muchas hagan un empeño formal en prepararse para ser dignas de una nueva gloria; pero si los planes no han de pasar de bellas teorías, no es razonable, Señores Editores, que malogremos nuestros conatos, y que nos hagamos aún más infelices por el íntimo conocimiento de la injusticia con que nos trata.

Como quizá pueda adivinarse, los prometidos planes de educación para mujeres no llegan a ver la luz en las páginas de El Observador. No solo porque algunos números después el semanario deja de salir (cuando su director se muda a otra provincia), sino probablemente porque la intención no era tanto instruir más al público femenino, ni concretar un plan de lecturas (como bien advierten las corresponsales cuando hablan de "ambigüedad), sino poner el relieve en los comportamientos sociales de las mujeres, recordándoles que sus conductas debían estar ceñidas a las prerrogativas del hogar y la familia. El Observador se propone, más bien, alertar, corregir las conductas desviadas de las mujeres. Pero sucede que en 1816 es difícil seguir eludiendo el tema de los "derechos", cuando se habla de educación. De allí la "ambigüedad" que detectan las lectoras en las páginas de este semanario que "promete"; pero no da, no formaliza un programa de lecturas. De la misma manera que reconoce la necesidad de instruir a las mujeres pero abomina de las que saben mucho. Y, en definitiva, opina que la ilustración femenina no es un modelo, sino una excepción que no necesita ser imitada. ${ }^{2}$

En el número siguiente, no obstante, hace su aparición otra lectora que firma como Emilia P. Dice pertenecer a la sociedad de Amigas del Observador y se singulariza del conjunto para sumar a lo dicho una anécdota: cuenta que paseando por la plaza del Retiro y habiéndose topado con un grupo de jóvenes distinguidos, reputados, de buen tono, escuchó tantos elogios a su hermosura "pero ninguno a mi talento, a mi cultura, a mi instrucción". Pese a que, tal como lo recomienda el semanario, ella se había ocupado muy bien de cultivarse y de empezar a leer "más libros útiles que novelas"; asegura sin embargo que esto no

2 Sobre el tema del "modelo" y la "excepción" en la Francia ilustrada y revolucionaria, puede consultarse el ya clásico ensayo de Geneviéve Fraisse, Musa de la razón: la democracia excluyente y la diferencia de los sexos (edición original de 1988). 
le dio todavía buenos resultados. A medida que la carta avanza, el tono de Emilia marcha de la ironía a la picaresca, para finalizar con una crítica a los hombres: dice que, en verdad, ellos no buscan el talento femenino. Y que, por ende, revolución sería cambiar lo que los hombres quieren de las mujeres, en vez de criticar o intentar corregirlas a ellas. Vale la pena ver cómo lo expresa Emilia:

Y bien, Sres. Editores: nosotras no podemos aspirar a los empleos, y acomodos que se apropiaron exclusivamente los hombres por la ley del más fuerte. A todo lo que aspiramos por primera y última felicidad es a un regular establecimiento: este depende de agradar a esos Señoritos: ellos no gustan sino del palmito. Bien pueden ser muy discretos, y de un finísimo talento; pero en su elección prefieren el mérito de nuestra figura al de la instrucción y talento. ¿Qué deberemos cultivar en este caso? Las letras, o las modas? Por dónde deberemos procurar nuestra fortuna puesta por desgracia en manos de sus caprichosos gustos? Por los libros, o por el tocador? Señores Editores: Udes. Tienen razón de aconsejarnos una mejor educación, pero tendrían mucha mayor, si tratan de reformar primero la educación de los jóvenes, que han de ser nuestros maridos, es decir, nuestros amos de por vida; porque según veo, todos los estados, todas las naciones, el universo todo podrá revolucionarse y mejorar; pero no habrá revolución, que mejore nuestra condición civil.

Esta lectora revierte imprevistamente el orden de la crítica que apunta el semanario. Y, al menos por un momento, dejan de estar las mujeres bajo la mirada de lo que hace falta corregir y reencauzar en ellas, para poner a los hombres en el banquillo de los acusados: $\mathrm{i}$ las letras o las modas? ¿Los libros o el tocador? ¿Qué desean, por fin, los hombres de las mujeres? Esas serían las preguntas que esbozan estos fragmentos. Si sumamos esos interrogantes al reproche de "ambigüedad" que aparecía en la carta de las corresponsales del número anterior tenemos por resultado la acusación de una suerte de histeria masculina que no hace más que trastornar a las mujeres y dañar a la sociedad que tanto desean resguardar (El Observador sería ambiguo porque promete y no da planes de educación, porque quiere y no quiere instruir a las mujeres).

Por supuesto, al número siguiente, el redactor se siente obligado a responder, primero amable y lisonjero, aclarando a las lectoras que los hombres, además de bellas, las quieren instruidas. Las dos cosas. Y luego volviendo sobre el número último de El Observador a las premisas básicas y un poco ambiguas que proponía asegura que la influencia de las mujeres se ejerce desde la domesticidad, a través de su desempeño como madres y esposas. Y aquí el redactor avanza un poco sobre la noción de libertad entre hombres y mujeres: ellas también "son parte 
del estado"; pero si no son instruidas, no amarán a la patria, reflexiona. Hasta allí arriba, el editor, prometiendo un "continuará" que se aborta, porque la publicación concluye con ese número. No habrá planes concretos ni definiciones a favor de la mujer ilustrada, todavía. Con todo, lo interesante de El Observador es que extiende el imaginario de la lectora de periódicos hacia una visión de conjunto: el colectivo de mujeres reunidas, es decir, una sociedad de lectura femenina que se desplaza cuando hace falta al terreno (a la práctica) de la escritura y de la crítica, a través de la corresponsalía. De tal manera este semanario introduce ya el tono de lo que serán, a partir de los años treinta, las polémicas desarrolladas en el interior mismo de la prensa, entre las primeras mujeres publicistas y sus interlocutores contemporáneos, a propósito de las mujeres sabias y las literatas (me refiero a las polémicas entre La Aljaba y La Argentina, o luego entre La Camelia y El padre Castañeta). ${ }^{3}$ También, en esos casos, el tono y la dinámica que articulan los debates ponen en juego la ironía y el sarcasmo, así como rayan la picaresca o la sátira. En las páginas de El Observador este recurso se presenta por primera vez mediante la voz de Emilia, circunscrito, todavía, al espacio restringido de la corresponsalía de lectoras, pero asumiendo ya un tono subido que se ampara en la convicción, por parte de las corresponsales, de que están reclamando una causa "justa".

\section{Lectoras de la vida real}

Ahora bien, ¿qué hay de real en esas figuraciones que esbozan los primeros semanarios porteños del XIX? Es decir, ¿ existen, fuera del papel, esas lectoras reunidas en sociedad que envían cartas al periódico o intercambian pareceres con una amiga suscriptora? $\mathrm{O}_{\mathrm{C}}$ son parte de un recurso editorial bien conocido y bastante utilizado en las primeras décadas del siglo por los publicistas? Francisco de Paula Castañeda, Luis Telma Pintos, Luis Pérez o el propio Domingo Faustino Sarmiento, un poco más tarde, impostaron la voz femenina, escribieron como si fueran "ellas" para llamar la atención de las lectoras a las que querían aleccionar. Así que si bien es difícil comprobar la autenticidad de esas cartas de mujeres publicadas en los primeros semanarios porteños del siglo XIX (y, de hecho, podríamos especular con que solo algunas son auténticas: quizá la de la Sociedad Amigas del Observador; mientras que en Correo es más probable que sea el propio Belgrano quien figura a sus corresponsales), lo cierto es que sí existía en Buenos Aires, ya

3 Desarrollo la cuestión en La mujer romántica. También pueden consultarse Francine Masiello, La mujer y el espacio público. El periodismo femenino en la Argentina del siglo XIX, y Néstor Auza, Periodismo y feminismo en la Argentina, 1830-1930. 
por entonces, una comunidad bien acotada de mujeres lectoras: una élite de señoras ilustradas y de jovencitas instruidas, provenientes de familias distinguidas, que fueron educadas en sus propias casas, al lado de institutrices o junto a sus padres, en las pláticas de los salones donde se conversaba asiduamente de libros, novedades culturales o política, y se leían y comentaban los periódicos.

Imposible no imaginar a una mujer como Mariquita Sánchez —o también a Melchora Sarratea o las Escalada (Remedios y Mercedes, esposa e hija del general San Martín), a Carmen Quintanilla, esposa del general Alvear- leyendo ávidamente la prensa para enterarse de las últimas noticias del día e imbuirse de la fe revolucionaria que pregonaban por entonces las páginas de La Gazeta de Buenos Aires. O, más adelante, entrada ya la década de los cuarenta y habiendo experimentado Mariquita en carne propia el exilio, sabemos que estaba siempre muy pendiente de las noticias que llevaban y traían los periódicos en las dos orillas del Plata, y que colaboraba intensamente con su hijo Juan Thompson (lo mismo que con los amigos románticos: Esteban Echeverría, Juan María Gutiérrez, entre otros), el cual estuvo al frente de un par de publicaciones opositoras al régimen, primero en la provincia de Corrientes y luego en Santa Fe (donde redactó, respectivamente, El Pueblo Libertador y El Libertador). Desde Montevideo, Mariquita le enviaba cartas y remesas con papel, lacre, tinta; le mandaba también diarios y noticias frescas que a ella le llegaban de Europa o de Buenos Aires, para que él pudiera componer sus propios escritos. Y hasta le daba consejos para desempeñar bien su oficio de publicista:

Mucho bien puedes hacer inspirando con destreza y dulzura cuanto tienda a moralizar, ilustra la sociedad y alejarla de ese abismo de odios y rencores a que la han conducido tantas causas que conoces como yo. Ten siempre un noble objeto en tus producciones y así siempre tendrás la recompensa en tu corazón y en el ánimo de los que lo tengan, con cuyo sufragio debes satisfacerte. Comprendo que una de tus penas será la sencillez y claridad con que deberás escribir para ser entendido; pero hay en la simplicidad también elegancia. (Mariquita Sánchez a Juan Thompson. Montevideo, 25 de febrero de 1840 , citada en Vilaseca 34-35)

Como vemos, Mariquita tiene una clara conciencia del mettier del escritor público en tiempos de guerra, así como del público al que van dirigidos sus escritos y, sin duda, de los asuntos que animan la política cotidiana del momento. No casualmente, durante esos mismos años, fue acusada de ser la anónima autora de algunos artículos conspirativos que circularon por las páginas de la prensa antirrosista y clandestina, cosa que ella nunca reconoció. 
El Nacional de hoy trae una carta de Bustamenta firmada, declarando ser falsa la que como suya ha publicado la Gaceta Mercantil [...]. Triste cosa que ni el consuelo de desmentir una calumnia bajo su firma le quede en esta época a una alma sincera. En igual caso me encuentro dándome por autora del Grito Sagrado, cosa que ni he soñado. Dirán que es mentira cuando lo asegure. ¡Nada nos deja la maldad, de que no abusen! (Mariquita Sánchez, Diario, 30 de abril de 1839, citada en Vilaseca, 382)

Lo que sí es seguro, y lo demuestran tantos otros fragmentos de su correspondencia y del Diario que escribe en los años cuarenta para su amigo Echeverría, es que Mariquita fue una diestra lectora de periódicos. Pero no fue una excepción. Ni en su ambiente, ni en el de las mujeres vinculadas a la cultura popular porteña de comienzos de siglo XIX. Como es el caso, por ejemplo, de Encarnación Ezcurra, la esposa de Juan Manuel de Rosas, que fue su más férrea colaboradora en los años que precedieron a su primer mandato de Gobierno. Ella lo ayudó a consolidar la red política que lo emplazó a él en el poder a comienzos de los años treinta, y fue la artífice de la Sociedad Popular Restauradora, que posteriormente dio vida a la mazorca. Cuando su marido marchó rumbo a lo que se daría en llamar primera campaña al desierto, que le depara gran protagonismo y éxito político, Encarnación se mantuvo en contacto con él a través de cartas que le escribía casi a diario. Y en las que le hacía llegar todo tipo de noticias de interés, también las que publicaban los periódicos a los que ambos prestaban una particular atención. Baste un solo ejemplo, salido de la correspondencia de Juan Manuel de Rosas, en noviembre de 1833, cuando le escribe a su esposa desde Río Colorado, pidiéndole más información y periódicos actualizados:

Y por lo que a mi toca ya sabes que hasta el cinco nomás tengo impresos y que no estaría de más me mandases los que han publicádose desde el seis adelante pues el señor Guido con la ocupación del Ministerio quizás no se acuerde de mandármelos, y también pueden venir truncos, lo que suele suceder siempre en las oficinas por los descuidos de los subalternos. (Juan Manuel de Rosas a Encarnación Ezcurra, noviembre de 1813, citado en Conde Montero)

Pero Encarnación no solo leía los periódicos y se los hacía llegar a Rosas adonde él estuviera, sino que se ocupaba de lo que estos tienen que decir acerca de su esposo, con una clara conciencia del rol que ejerce la prensa en el rumbo de la vida política y social:

Dime pues en qué ha consistido [...] si en los periódicos está impresa conforme yo la mandé en tal caso nada digo. También quisiera saber cómo ha 
sido recibida. En los paisanos pobres ya sé que ha de haber agradado; pero como ningún caporal ni de los amigos ni de los enemigos me han dicho nada sobre ella, deseo que me digas cómo han opinado y qué han dicho. (Juan Manuel de Rosas a Encarnación Ezcurra, noviembre de 1813, citado en Conde Montero)

Encarnación sabía medir el impacto de la prensa política entre los lectores de diferente extracto sociocultural, más específicamente, ella se encargaba en persona de testear la imagen de Rosas que por entonces iban articulando las noticias periodísticas. Fue, por eso mismo, su interlocutora más idónea, su confidente, la que había aprendido - instruida por el propio Rosas- a priorizar el diálogo con los sectores más carenciados de la población, apostando a eso el futuro político de su marido. Supo, además, enfrentar las habladurías de los enemigos, que no lograban amedrentarla a pesar de los condicionamientos a los que necesariamente la exponía su género: "esta pobre ciudad no es ya sino un laberinto; todas las reputaciones son el juguete de estos facinerosos, por los adjuntos papeles veras como anda la reputación de tu muger y mejores amigos; mas a mi nada me intimida. Yo me sabré hacer superior a la porfía de estos malvados y ellos pagaran bien caro sus crímenes", le escribe Encarnación a su marido, en carta del 2 de octubre de 1833, haciendo gala de su valentía.

Ahora bien, más allá de estos dos casos de mujeres fuertemente comprometidas con la vida política que se valieron para ello de su condición mujeres letradas (el caso de Encarnación Ezcurra, en diálogo con los sectores populares, y el de Mariquita Sánchez, inserta en la cultura de la élite), lo cierto es que tal como lo demuestran las primeras representaciones periodísticas desde comienzos de siglo XIX, el ascenso de la mujer lectora más bien buscó amparo o legitimidad en el perfil emergente de la patriota. Ya en 1812, Mariquita Sánchez y otras conocidas mujeres de su ambiente se ocupaban de hacer aparecer sus nombres en las páginas de la Gazeta de Buenos Aires, tras declarar su compromiso con la causa revolucionaria. Fueron ellas: Tomasa y María de la Quintana; Remedios, Nieves y María Eugenia de Escalada; Ramona Ezaquibel y Aldao; Pertena Cárdenas; Rufina de Orma; Isabel Calvamentes de Agrelo; María de la Encarnación Andonaegui; Magdalena Castro; Ángela Castelli de Igarzábal, y Carmen Quintanilla de Alvear. Estas damas de la élite porteñas hicieron conocer a la prensa la decisión de vender sus joyas y donar el dinero obtenido para la compra de armamentos que iban a abastecer al ejército revolucionario. Al tiempo que declaraban públicamente su compromiso con la causa, aprovecharon para poner de manifiesto su necesidad de salir del coto invisible de la domesticidad e ingresar, aunque 
sea simbólicamente, en el terreno de lo público. Así comienza una extensa carta firmadas por ellas, que publicó en su número 12 la Gazeta Ministerial el 26 de junio de 1812:

Destinadas por la naturaleza y por las leyes a llevar una vida retirada y sedentaria, no pueden desplegar su patriotismo con el esplendor que los héroes en el campo de batalla. Saben apreciar bien el honor de su sexo a quien confía la sociedad el alimento y educación de sus jefes y magistrados, la economía, y el orden doméstico, base eterna de la prosperidad pública; pero tan dulces y sublimes encargos no las consuelan apenas en el sentimiento de no poder contar sus nombres entre los defensores de la libertad patria. En la actividad de sus deseos han encontrado un recurso, que siendo análogo a su constitución desahoga de algún modo su patriotismo.

Claro que el "recurso" al que apelan estas damas no se agota en el dinero obsequiado para la compra de armamentos, sino que aprovechan la ocasión para hacerse oír públicamente. El patriotismo legitima este anhelo, habilita a las mujeres para salir del dominio exclusivo de la domesticidad, del ámbito de lo privado, y mostrar que ellas no son ajenas al juego político que se entabla por esos días en las páginas de la prensa oficial. Recordadas como "las patricias" argentinas, esas mujeres que firman la carta enviada a la Gazeta en mayo de 1812 fueron también lectoras y ocasionalmente corresponsales de los periódicos de comienzos de siglo. A juzgar por su corta pero incisiva aparición en la prensa, ellas delinearon sobriamente la silueta de la lectora patriota que los líderes de Mayo propiciaban hacia 1810, y que no solo fue ensalzada algunas décadas más tarde por los escritores románticos, sino que volvió a hacerse presente cada vez que fuera necesario legitimar la figura de la mujer letrada a lo largo de la centuria.

\section{Obras citadas}

Auza, Néstor. Periodismo y feminismo en la Argentina, 18301930. Buenos Aires: Emecé, 1988. Impreso.

Batticuore, Graciela. La mujer romántica: lectoras, escritoras y autores en la Argentina. 1830-1870. Buenos Aires: Edhasa, 2005. Impreso.

Bollman, Stefan y Elke Heidenreich. Las mujeres que leen son peligrosas. Madrid: Maeva, 2006. Impreso.

Catelli, Nora. Testimonios tangibles: pasión y extinción de la lectura en la narrativa moderna. Barcelona: Anagrama, 2001. Impreso.

Chartier, Roger. El mundo como representación: historia cultural. Entre práctica y representación. Barcelona: Gedisa, 1995. Impreso. 
Conde Montero, M. "Correspondencia inédita de la Revista Argentina de Ciencias políticas, año XIV, tomo XXVII, n. 149". Web.

Correo del Comercio de Buenos Aires, 28 de abril de 1810, número 9 tomo I, 69. Impreso.

Correo del Comercio de Buenos Aires, 5 de mayo de 1810, número 10, tomo I, 76. Impreso.

"Educación de las mujeres". Semanario de Agricultura, Industria y Comercio, 30 de mayo de 1804, número 89, Tomo 2, folio 305. Impreso.

Flint, Kate. The Woman Reader: 1837-1914. New York:

Oxford University Press, 1993. Impreso.

Fraisse, Geneviéve. Musa de la razón: la democracia excluyente y la diferencia de los sexos. Madrid: Cátedra-Universidad de Valencia, 1991. Impreso.

Masiello, Francine. La mujer y el espacio público: el periodismo femenino en la Argentina del siglo XIX. Buenos Aires: Feminaria, 1994. Impreso.

Perrot, Michelle. Mujeres en la ciudad. Barcelona: Andrés Bello, 1997. Impreso.

Vilaseca, Clara. Cartas de Mariquita Sánchez. Buenos Aires: Peuser, 1951. Impreso.

Zanetti, Susana. La dorada garra de la lectura: lectoras y lectores de novela en América Latina. Rosario: Beatriz Viterbo, 2002. Impreso. 